\title{
Careful Price Level Targeting
}

\author{
George A. Waters* \\ Department of Economics \\ Campus Box 4200 \\ Illinois State University \\ Normal, IL 61761-4200
}

September 30, 2012

\begin{abstract}
This paper examines a class of interest rate rules that respond to public expectations and to lagged variables. Varying levels of commitment correspond to varying degrees of response to lagged output and targeting of the price level. If the response rises (unintentionally) above the optimal level, the outcome deteriorates severely. Hence, the optimal level of commitment is sensitive to the method of expectations formation and partial commitment is the robust, optimal policy.

Keywords: Learning, Monetary Policy, Interest Rate Rules, Commitment, Price Level Targeting

JEL classification: E52, E31, D84
\end{abstract}

*gawater@ilstu.edu 


\section{Introduction}

Under rational expectations, commitment by a monetary policymaker to an interest rate rule that targets the level of an aggregate price index can lead public expectations to respond to shocks in a desirable way (Woodford 1999, 2003). However, such rules must be history dependent, and the proper degree of response to lagged variables is sensitive to the underlying modeling assumptions, in particular, the method the public uses to form expectations.

Evans and Honkapohja $(2002,2006)$ study a class of interest rate rules that respond to public expectations and lagged output and shows that they have the desirable properties of determinacy and expectational stability for a wide range of parameter values under both commitment and discretion. The present work examines a broader class of such rules to include a range of levels of commitment, which corresponds to the degree of the response to lagged output, and their performance under varying assumptions about expectations formation.

The optimality of a high degree of commitment, as advocated by Blake (2001) and McCallum and Jensen (2002), obtains when public expectations are formed with least squares learning, but this result is fragile. Outcomes across varying levels of commitment are asymmetric in that over-commitment can lead to large fluctuations in inflation and output. Hence, unless the policymaker has precise information about the underlying model, high degrees of commitment are problematic. With the inclusion of errors in the policy rule, the policymaker should adopt a lesser degree of commitment, corresponding to a smaller magnitude of response to lagged output in the interest rate rule. If expectations are formed adaptively, a la Cagan (1956), the case for any level of commitment is weakened considerably.

Such commitment implies that the policymaker is acting to affect the price level, not just inflation. In Woodford's $(1999,2003)$ baseline model, commitment is equivalent to targeting a fixed price level. Under an intermediate level of commitment, referred to as partial commitment here, the policymaker acts to adjust the price level, but does not make an effort to return it all the way to a pre-determined target. A comparison is made both analytically and using impulse response functions for one calibration of the model.

\section{The model}

The core of the model is the standard New Keynesian, expectations augmented IS and Phillps Curve relations including a cost-push (supply) shock $u_{t}$.

$$
x_{t}=-\varphi\left(i_{t}-E_{t}^{*} \pi_{t+1}\right)+E_{t}^{*} x_{t+1}
$$




$$
\pi_{t}=\lambda x_{t}+\beta E_{t}^{*} \pi_{t+1}+u_{t}
$$

The variables $x_{t}$ and $\pi_{t}$ are the deviations of output and inflation from their target values. The notation $E_{t}^{*}$ indicates private sector expectations formed in time $t$ where the $(*)$ is used to show that expectations might not be rational. The parameters $\varphi, \lambda, \beta$ are all positive and the discount rate $\beta$ is such that $\beta<1$.

The policymaker sets the nominal interest rate to stabilize the endogenous variables. Formally the task is to set $i_{t}$ to minimize the loss function

$$
L=E_{t} \sum_{s=0}^{\infty} \beta^{s}\left(\pi_{t+s}^{2}+\alpha x_{t+s}^{2}\right)
$$

The parameter $\alpha$ indicates the relative importance of inflation and output stabilization. Minimizing the loss function at time $t$ constrained by the Phillips curve (2), while taking expectations to be fixed, yields the following.

$$
\lambda \pi_{t}+\alpha x_{t}=0
$$

Such discretionary policy does not consider the effect on future expectations and so is not optimal under rational expectations. The optimal commitment policy, which does account for the reaction of the public, takes the form

$$
\lambda \pi_{t}+\alpha\left(x_{t}-x_{t-1}\right)=0
$$

Policy under commitment is not time consistent as, in a given period, discretionary policy produces superior inflation and output outcomes. Thus, a policymaker under commitment is said to have a timeless perspective.

The following condition allows for a study of a range of commitment.

$$
\lambda \pi_{t}+\alpha\left(x_{t}-\kappa x_{t-1}\right)=0
$$

where discretion is a special case of (6) where $\kappa=0$, and full commitment is equivalent to setting $\kappa=1$. Here, the level of commitment corresponds to the degree that the policymaker takes lagged information into account. Policies that satisfy the condition (6) at an intermediate level of $\kappa$, where $0<\kappa<1$, are particularly interesting in an environment where public agents do not have fully rational expectations. The gains to commitment depend on the effect on expectations so different assumptions about the formation of expectations could lead to different conclusions. Also, Blake (2001) and McCallum and Jensen (2002) advocate for the value $\kappa=\beta$ based on a loss function without discounting on the grounds that such an approach better represents the timeless perspective. This policy is called modified commitment, and a 
policy using any value of $\kappa$ below, $0<\kappa<\beta$ is called partial commitment.

The resulting interest rate rule is determined by the general condition (6) and the IS relation (1). As in Evans and Honkapohja (2004) and Woodford (2003), the interest rate responds directly to observed public expectations. The alternative is to impose rational expectations and express expected inflation and output in terms of current variables. Evans and Honkapohja (2004) refer to such rules as "fundamentals based" and show that for a range of parameter values they lead to model specifications that are neither determinate or learnable. The expectations based interest rate rule is

$$
i_{t}=\delta_{L} x_{t-1}+\delta_{\pi} E_{t}^{*} \pi_{t+1}+\delta_{x} E_{t}^{*} x_{t+1}+\delta_{g} g_{t}+\delta_{u} u_{t}
$$

where the coefficient on the lagged output term is

$$
\delta_{L}=\frac{-\kappa \alpha}{\varphi\left(\lambda^{2}+\alpha\right)}
$$

The parameter $\delta_{L}$ is the only one in (7) that depends on the commitment parameter $\kappa$, so the level of commitment corresponds to the magnitude of the response to the interest rate to $x_{t-1}$. Again, under discretion $(\kappa=0)$ there is no response, while full commitment $(\kappa=1)$ represents the greatest response a policymaker would knowingly make.

I say "knowingly", since the possibility that the policymaker over-responds is a serious concern. To have precise knowledge of the correct value of $\delta_{L}$ requires that policymaker understands connection between the policy rate and the economy and knows the values of the output gap and the parameters. Waters (2009) shows that setting $\delta_{L}$ corresponding to a value $\kappa>1$ (inadvertently) could create indeterminacy and explosive solutions.

Proposition 1 (Waters 2009) Under rational expectations, there exists a non-explosive and determinate solution to the model defined by (1), (2) and (7) if $0<\kappa<1+\frac{\lambda^{2}}{\alpha(1-\beta)}$.

The solution is learnable for any $\kappa \geq 0$.

In one sense, the above result is positive, since it ensures unique, stable and learnable ${ }^{1}$ solutions for the present class of interest rate rules. For a conservative central bank, meaning $\alpha$ is small, the bound above may not be a major concern, but for a policymaker who does place significant emphasis on output stabilization, the bound is only slightly above 1 .

To analyze the quantitative importance of potentially over-reaction of the interest rate to lagged output, Waters (2009) simulates the model where public expectations are formed using least squares learning. For

\footnotetext{
${ }^{1}$ Here, learnable means expectationally stable as defined by Evans and Honkapohja (2004).
} 
the model given by the IS (1) and Phillips Curve (2), the minimum state variables solution has the following form.

$$
\begin{aligned}
& x_{t}=b_{x} x_{t-1}+c_{x} u_{t} \\
& \pi_{t}=b_{\pi} x_{t-1}+c_{\pi} u_{t}
\end{aligned}
$$

Agents use a model with the same for structure as above for forecasting output and inflation and update their estimates of the coefficients $\left(b_{x}, b_{\pi}, c_{x}, c_{\pi}\right)$ of the model using OLS on a rolling window of past data, i.e. constant gain learning. Figure 1 shows the mean $\operatorname{losses}^{2}$ for a range of values of $\kappa$ representing commitment and $\alpha$ representing the conservatism of the policymaker.

\section{Figure 1}

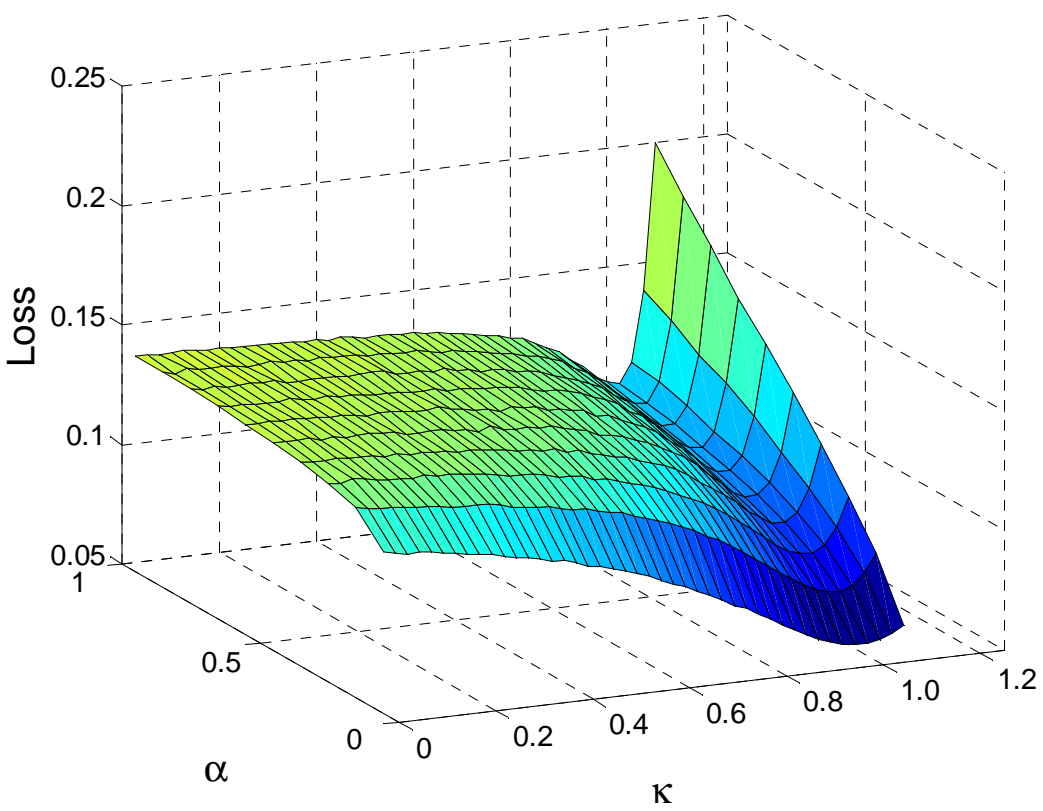

Policy outcomes under least squares learning

The gains to commitment are clear in the figure. For any $\alpha$, the loss is minimized near the full commitment level of $\kappa=1$ and the discretionary outcome $(\kappa=0)$ is at least $50 \%$ worse as measured by the loss. Close examination of the results shows that the modified commitment setting $\kappa=\beta=0.99$ is best for any $\alpha$. However, in the neighborhood of this loss-minimizing policy, there is notable asymmetry across the levels of commitment. As the commitment level rises above the loss minimizing level, the deterioration of the loss is much greater than if the level falls, particularly for larger values of $\alpha$, in line with Proposition 1 . While

\footnotetext{
${ }^{2}$ The mean is over 10,000 runs of 200 periods each. The parameter values are taken from McCallum and Nelson (2004).
} 
the results shown in Figure 1 confirm the optimality of commitment, they do not ameliorate concerns about the necessary precision of knowledge about the model.

A natural next step to examine the issue of the knowledge of the policymaker is to include an error term in the interest rate rule (7). Such shocks arise due to measurement error of the public expectations or the output gap. Furthermore, there is uncertainty about the impact of changes in the policy rate on the broader economy. Figure 2 reports policy outcomes across varying levels of commitment where half the volatility from demand shocks comes from the policy rule errors. For ease of comparison, for each choice of $\kappa$, the outcome is reported as the ratio of the loss with its value under discretion, $\kappa=0$. While modified commitment $(\kappa=0.99)$ is still best for lower levels of $\alpha$, when the policymaker places significant emphasis on output stabilization a lower level of commitment is optimal. For example, when the parameter $\alpha$ is set to an intermediate value $\alpha=0.25$, the optimal level of commitment falls to the partial commitment value $\kappa=0.91$, and the improvement over discretion is comparatively modest. Summarizing results reported in Figure 2 and Waters (2007), larger shocks to the policy rule and a less conservative central banker implies a lower optimal level of commitment.

\section{Figure 2}

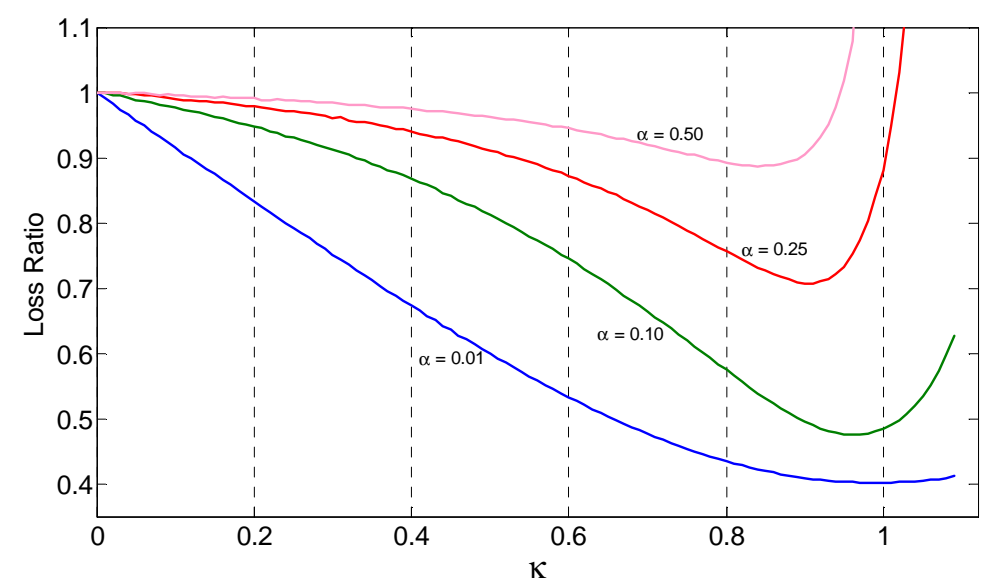

Policy outcomes under least squares learning with policy rule shocks

Furthermore, the optimal level of commitment depends on the information and methods used by the public to form expectations. In simulations with least squares learning, the gain parameter is a key value that determines the emphasis the policymaker places on recent information. One can interpret the gain parameter as a measure of credibility, low gain meaning that the public trusts the policymaker's ability and desire to respond to shocks so recent information has a limited effect on forecasting procedures. The value of 0.15 in the simulations discussed in Figures 1 and 2 is one of the higher values found in the literature, but, in the presence of policy rule errors, some degree of partial commitment is still optimal for the lower 
value of 0.025 , even with a conservative central banker $(\alpha=0.01)$. Results with the high gain parameter are important considering the potential for external factors, such as a financial crisis, to affect the credibility of the policymaker. A potentially fruitful extension would be to make the gain parameter endogenous, as in Marcet and Nicolini (2004), where the gain falls over time unless there is a large forecast error in a given period, when the gain reverts to a higher level. Such an approach captures the idea that credibility builds slowly over time, but can be lost quickly.

Broadening the discussion to other approaches to expectations formation, under rational expectations, modified commitment is best even with policy rule errors. However, the asymmetry shown in Figure 1 still exists and partial commitment may be optimal in the presence of policymaker uncertainty about model parameter values, as shown in Waters (2011). Under adaptive expectations, as introduced by Cagan (1956) where the expectation of a variable is a weighted average of the realization and expectation from the previous period, the case for modified or full commitment is weaker. Compared to least squares learning, as used to generate the simulation results in Figures 1 and 2, under adaptive expectations agents are less sophisticated in their use of information when forming expectations and the case for partial commitment becomes stronger. For the case discussed above $(\alpha=0.25)$, the optimal level of commitment is is much lower at $\kappa=0.6$ and the loss under discretion is typically less that $12 \%$ worse than the optimal partial commitment outcome, even though there are no policy rule errors in the simulations with adaptive expectations. The case for full or modified commitment depends on a public being sophisticated in their method of expectations formation and the policymaker having a high degree of confidence in their model.

Note that determinacy is not an issue in any of these simulation results. The model that agents use to make forecasts (the "perceived law of motion") does not allow for extraneous variables that could introduce alternative solutions. Consideration of such solutions would further weaken the case for full commitment. For the results in Figures 1 and 2, modified commitment is not optimal for some parameter values due to the interaction of the learning mechanism and the policy rule errors.

\section{Partial commitment in practice}

The difference between discretion and commitment of the type analyzed here is often characterized by the resulting response of the price level to supply shocks under these policies. Under full commitment $(\kappa=1)$, the policymaker acts to completely undo the effect of the supply shock and return the price level to its former value. Under discretion, the policymaker is unconcerned about the price level and the impact of a supply shock is permanent. The policymaker using partial commitment does act to counter the change in the price level, but target value is in between the original target and the value under discretion. 


\section{Figure 3}
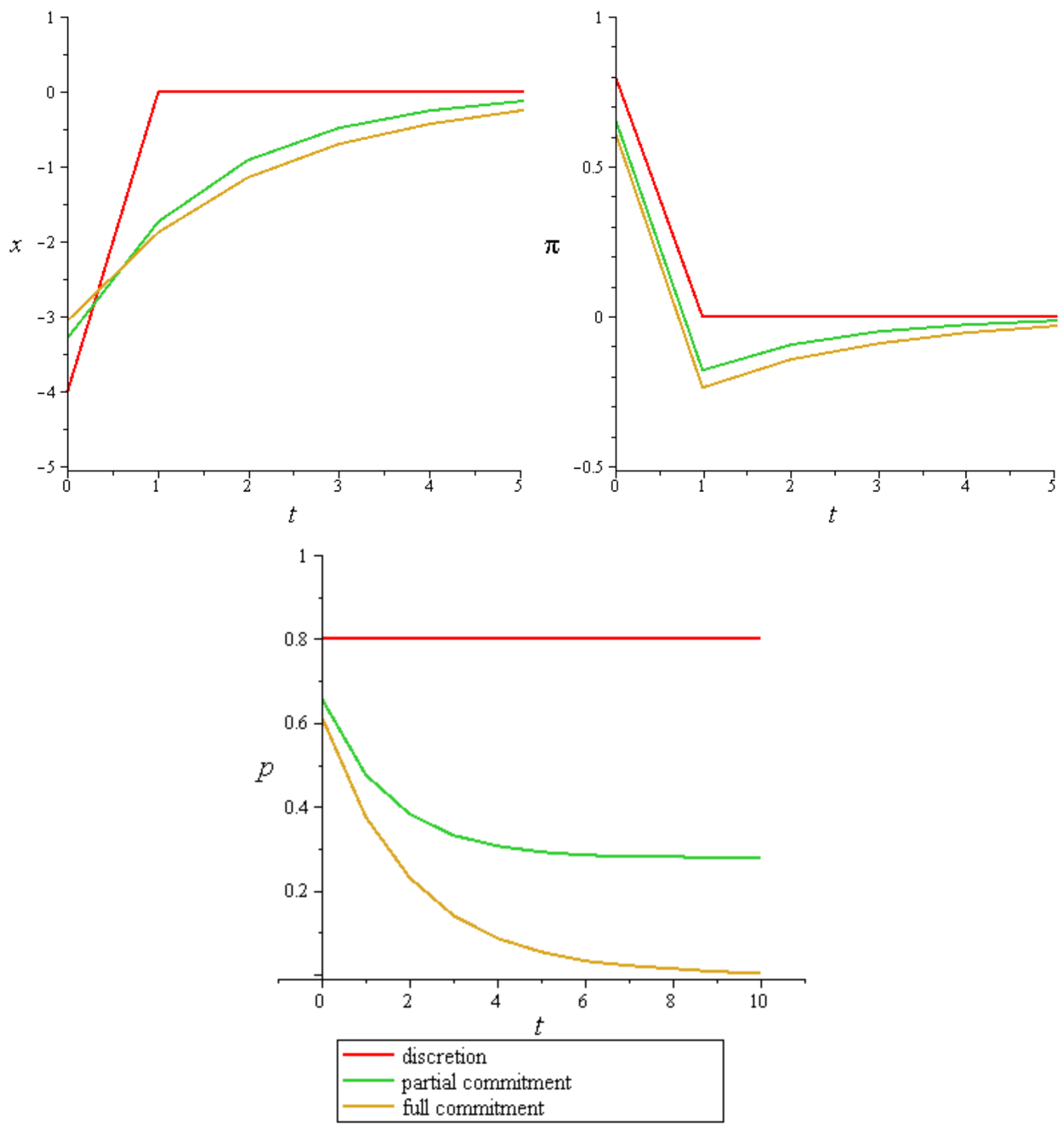

Impluse Responses to a Supply Shock

To illustrate policies under varying degrees of commitment, Figure 3 shows impulse responses ${ }^{3}$, assuming rational expectations, to an unforecastable., single period supply shock $u_{0}=1$ under discretion, partial commitment and full commitment, the parameter $\kappa=0.0,0.8$ and 1.0, respectively. The starting, target level for all variables is zero, and the immediate effect of the shock is to increase inflation and the price level and to decrease output. The result of the discretionary policy is to immediately return inflation to zero, so the policymaker makes no effort to counter the change in the price level, which remains constant past period 1. In contrast, under full and partial commitment, the policymaker does act to lower the price level, meaning

\footnotetext{
${ }^{3}$ This exercise follows Woodford $(1999,2003)$. Note that partial commitment is different than the "hybrid" policy in the former paper.
} 
inflation falls below zero beyond the first period. The benefit of commitment is apparent in all three graphs. Since public expectations take the policymaker's commitment into account, the affect of the shock to each variable in period 0 is mitigated compared to the outcome under discretion. The primary difference between full and partial commitment is apparent in the response of the price level. Considering the inflation and output graphs, the contrast between partial and full commitment appears to be modest. The initial effects of the shock are larger under partial commitment, compared to full commitment, but the difference is slight compared to the outcome under discretion. There is a fundamental difference in the response of the price level under partial commitment in that it does not return all the way to zero. While the policymaker does respond to the price level under partial commitment, the policy cannot be characterized as having a fixed price level target.

One can derive the asymptotic value of the price level for any level of commitment $\kappa$.

Proposition 2 For the model given by (1) and (2) with the minimum state variables solution (8) under rational expectations, if the initial price level is zero, $p_{-1}=0$, and the shocks $u_{t}$ are serially independent, the coefficients $b_{x}$ and $c_{\pi}$ are such that $0<b_{x}<1$, and $c_{\pi}>0$. The long run price target under the interest rate rule (7) is

$$
\bar{p}=\lim _{t \rightarrow \infty} p_{t}=c_{\pi}\left(\frac{1-\kappa}{1-b_{x}}\right) .
$$

The long run price target is inversely related to the level of commitment.

$$
\frac{d \bar{p}}{d \kappa}<0
$$

Clearly, under full commitment ( $\kappa=1$ ), the long run value of $p_{t}$ is zero, and the policymaker is targeting a fixed price level. However, under partial commitment $(0<\kappa<1)$, the long run target is positive, so the policymaker is not acting to return the price level to its initial level. As the degree of commitment falls away from full commitment, the higher the long run price target is for the case of a one-time shock.

While a policy that can be simply characterized is desirable, the lack of a fixed price level target is not a serious reason to dismiss partial commitment. Beyond the concerns about the information available to the public and policymaker expressed above, Woodford (2003) identifies other reasons that the desirability of a fixed price level target requires particular modeling assumptions. If the loss function captures a benefit to interest rate stabilization or if hitting the zero lower bound on interest rates is possible, even full commitment would not be equivalent to a fixed price level target. In practice, the policymaker would publish forecasts for the price level, as does the Bank of England and Norges Bank (Norway), that allow for the target to vary. 


\section{Conclusion}

There are clear gains to commitment to a interest rate rule that responds to lagged output in a way that constrains public expectations. Such rules differ from discretion in that they respond to changes in the price level. Nevertheless, these gains and the optimal degree of commitment is sensitive to assumptions about expectations formation and the policymaker's estimates of those expectations, as well as the structure and parameter values of the model being used. The potential for very poor outcomes if the response to lagged variables is excessive, i.e. over-commitment, means that it is essential for the policymaker to know that such a policy is robust to a variety of modeling assumptions.

The present work focuses on some different ways the public can form expectations, though the list is hardly exhaustive, and there are other modeling choices to be considered. One could extend the analysis to include heterogeneous expectations or Bayesian updating when the correct model specification is uncertain.. There are alterative versions of the underlying model that include capital in production or interest rate smoothing, to note two examples.

These concerns about commitment are arguments concerning the long run strategy for monetary policy. Given special circumstances, such as concern about deflation or the zero lower bound on interest rates, a policymaker could announce a short run price level target if the usual rule-based procedures to not apply. The primary message is that, while countering price level movements is a potentially important tool for monetary policymakers, there is a real danger to overdoing it, and the policymaker should be confident that the gains to such a policy exist under all reasonable modeling assumptions, particularly those related to expectations.

\section{References}

Barro, Robert J. and David B. Gordon (1983) A Positive Theory of Monetary Policy in a Natural Rate Model. Journal of Political Economy 91, 589-610.

Blake, A. P. (2001) A 'Timeless Perspective' on Optimality in Forward-Looking Rational Expectations Models. Working Paper, National Institute for Economic and Social Research.

Bullard, James and Kaushik Mitra (2002) Learning about Monetary Policy Rules. Journal of Monetary Economics 49, 1105-1129.

Cagan, Phillip (1956). "The Monetary Dynamics of Hyperinflation." in Studies in the Quantity Theory of Money, ed. Milton Friedman, University of Chicago Press, Chicago.

Clarida, Richard and Jordi Gali and Mark Gertler (1999) The Science of Monetary Policy: A New Keynesian Perspective. Journal of Economic Literature 37, 1661-1707.

Clarida, Richard and Jordi Gali and Mark Gertler (2000) Monetary Policy Rules and Macroeconomic Stability: Evidence and Some Theory. Quarterly Journal of Economics 115, 147-180. 
Evans, George and Seppo Honkapohja (1993) Adaptive Forecasts, Hysteresis and Endogenous Fluctuations. Federal Reserve Bank of San Francisco Economic Review 1993(1), 3-13.

Evans, George and Seppo Honkapohja (2001) Learning and Expectations in Macroeconomics. Princeton University Press, Princeton, NJ.

Evans, George and Seppo Honkapohja (2003) Expectations and the Stability Problem for Optimal Monetary Policies. Review of Economic Studies 70, 807-824.

Evans, George and Seppo Honkapohja (2006) Monetary Policy, Expectations and Commitment. Scandinavian Journal of Economics 108, 15-38.

Evans, George and Bruce McGough (2004) Monetary Policy, Indeterminacy and Learning. Journal of Economic Dynamics and Control 29, 1809-1840.

Evans, George and Bruce McGough (2006) Optimal Constrained Interest Rate Rules. Journal of Money, Credit and Banking, forthcoming.

Honkapohja, Seppo and Kaushik Mitra (2004) Are Non-Fundamental Equilibria Learnable in Models of Monetary Policy? Journal of Monetary Economics 51(8), 1743-1770.

Jensen, Christian and Bennet McCallum (2002) The Non-Optimality of Proposed Monetary Policy Rules Under Timeless-Perspective Commitment. Economics Letters, 77(2), 163-168.

Marcet, Albert and Juan Nicolini (2004) Recurrent Hyperinflations and Learning. American Economic Review 93(5), 1476-1498.

McCallum, Bennet T. (1983) On Non-uniqueness in Linear Rational Expectations Models: An Attempt at Perspective. Journal of Monetary Economics 11, 139-168.

McCallum, Bennet T. and Edward Nelson (2004) Timeless Perspective vs. Discretionary Monetary Policy in Forward Looking Models. Federal Reserve Bank of St. Louis Review 86(2), 43-56..

Orphanides, Athanios and John C. Williams (2002) Imperfect Knowledge, Inflation Expectations and Monetary Policy. NBER Working Paper 9884.

Orphanides, Athanios and John C. Williams (2006) Monetary Policy with Imperfect Knowledge. Journal of the European Economic Association 4(2-3), 366-375.

Walsh, Carl E. (2003) Monetary Theory and Policy. MIT Press, Cambridge, MA.

Waters, George (2007) Regime Changes, Learning and Monetary Policy. Journal of Macroeconomics 29(2), $255-282$

Waters, George A. (2005) Dangers of Commitment: Monetary Policy with Adaptive Expectations. Journal of Economics and Finance 30(1),93-104.

Waters, George A. (2009) Learning, Commitment and Monetary Policy. Macroeconomic Dynamics 13(4), $421-449$.

Waters, George (2011) Dangers of Commitment under Rational Expectations. Journal of Economics and Finance 35(4), 371-381.

Woodford, Michael (1999b)Commentary: How Should Monetary Policy Be Conducted in an Era of Price Stability? In New Challenges for Monetary Policy, pp. 277-316, Federal Reserve Bank of Kansas City.

Woodford, Michael (2003) Interest and Prices. Princeton University Press, Princeton, NJ. 